\title{
Exploration and Practice of Research-based Teaching on Basic Chemistry Experiment in Local Colleges and Universities
}

\author{
Lijuan Ye, Wenqi Liu and Jianhong Jiang * \\ College of Chemistry biology and Environmental Engineering, Xiangnan University, Chenzhou, \\ 423043, Hunan ,China \\ yelijuan68116@163.com \\ *The correspondence Author
}

Keywords: Local colleges and universities; Basic chemistry; Experiment; Research-based teaching

\begin{abstract}
This paper analyzed the main problems existed in basic chemistry experiment teaching, expounded the connotations and basic principles of research-based teaching, constructed a new model of basic chemistry experimental research-based teaching. This new model includes the integration and optimization of the contents of the experimental course; the combinations of class and out of class, the training level of basic chemistry experiment, extracurricular scientific project training and multi-platform scientific and technological innovation; reform of ways of problem solving, project participating, scientific and technological innovating, especially the independent innovation, assessment and evaluation of students.
\end{abstract}

\section{Introduction}

Research-based teaching is student-centered and teacher-led, which advocates to guide students to focus on study and exploration, makes students become active participants in discovery, understanding, evaluation and application of knowledge in learning. It pays attention to training students equipped with the abilities of raising, analyzing and solving questions, and innovating. In order to adapt to the development of social economy at home and abroad, achieve the dream of the Chinese nation, China's universities urgently need to promote the teaching reform vigorously, carry out the corresponding new education and train high-quality innovative talents.

Chemistry is an experimental discipline, chemistry experiment also plays a role in imparting knowledge, training scientific methods and thinking, improving the senses of innovation and the abilities of innovation and practice, training scientific spirits. The local colleges and universities explore and practice basic chemistry experimental research-based teaching, which is not only to conform to the national development strategy in the new period but an effective way to train innovative talents of chemistry and chemical engineering. And it is the inevitable choice to imply the party and the state education policy, achieve the great rejuvenation of the Chinese nation in addition. In the past a long period of time, there are three main problems of the four basic chemistry experiment teaching:

(1) All the experimental courses are attached to the theoretical course of the same name. The arrangement of experimental contents is unscientific. The proportion of the verifiable experiment is too high, and the proportion of the comprehensive, designed and applied experiment is very low, which is not conducive to cultivating the students' abilities to discover, analyze and solve the problems.

(2) The experimental contents are so obsolete and the teaching process is too procedural that students are often just step by step passively, the student's dominant position has not been highlighted. It also limited the subjective initiative of students and the leading role of teaches.

(3) Teachers lack of in-depth study of teaching methods, experimental means, new technologies, and new trends. The phenomenon that teachers replay in experimental teaching perfunctorily, leading the experimental teaching quality and ability hardly improved, students' experimental level and abilities at low level, which is not conducive to cultivating students' innovative abilities. 
In summary, the present situation of basic chemistry experiment teaching has not accorded with the rule of chemistry discipline, which not only affects the quality of basic chemistry teaching, but restricts the cultivation of innovative talented students. Therefore, the teaching reform of basic chemistry experiment is imminent and imperative.

\section{Relative Theory Foundations}

The Connotation of Research-Based Teaching. Research-based teaching refers to the students actively explore and solve the problems by scientific research ways under the guidance of teachers. It can help students to achieve knowledge acquisition and application, and cultivate the spirits and abilities of innovation. Research-based teaching is a process of learning between teachers and students, and it is also a practical process for teachers and students to work together to carry out the determination of contents, the choice of methods and the cooperation and communication with each other to solve the problems.

The Essential Features of Research-Based Teaching. (1) Openness: Research-based openness includes the teaching contents, process and the openness of the teaching organization.

(2) Research: Research-based teaching is a kind of teaching which includes both teaching and scientific research under the guidance of teachers, demanding teachers' researchful teaching and students' researchful learning.

(3) Autonomy: Research-based teaching is a process of self-exploration, based on the students' existing knowledge and experience. From the formation of research questions to the collection and collation of research information, the writing of research reports, the display of results, etc, meanwhile, students can make independent decisions according to their own interests, hobbies, and teachers only play as mentors and assistants.

(4) Practicality: Research-based teaching emphasizes the relationship between theory and practice, focusing on the close combinations of theory, socioeconomic development and the reality of life.

The principle of research-based teaching. (1) Combination of teaching and research: The first one is the combinations of teaching and research contents. The second one is organization of research-based teaching activities. The third one is advocating students to participate in research activities actively.

(2) Integration of theory and practice: Guiding students to pay attention to social and real life issues, and actively participate in social practice, which improves the practical abilities and innovative spirits of students.

(3) Combination of class and extracurricular activities: Combining both in class and after the class well, coordinate with each other and work together.

\section{Research-based Teaching Practice of Basic Chemistry Experiment}

Integration and Optimization of Experimental Course Contents. "Inorganic Chemistry and Chemical Analysis, Organic Chemistry and Physical Chemistry" in the talent training program were integrated and basic chemistry experiment course was set up individually. We take the connections of synthesis, separation, purification, analysis, practice and application as core contents, and then divide the experimental contents into six modules: "basic skills in chemical experiments" , "qualitative analysis and identification of elements and compounds", "basic synthesis and preparation" "measure of physical quantities and parameters"and "comprehensive chemistry experiment". The basic chemistry research-based experimental teaching system was formed with "three stages, six modules" feature, and the "synthesis and preparation - analysis and characterization - performance application" is used as the main line. According to the knowledge level, the experimental course is divided into three stages: "foundation - improvement innovation". We focus on training students familiar with the basic operation to improve hands-on abilities during basic stage, focus on developing students' abilities to use professional knowledge to analyze and solve problems during improved stage and rely on innovative research experiments to 
focus on cultivating comprehensive thinking and innovation of students during innovation stage.

A New Teaching System of "One Integration, Two Approaches, the Three Levels and the Three Modes". We adhere to the people-oriented concept, attach importance to scientific research abilities and cultivate the spirits of innovation, set up a new teaching concept, emphasize the interaction and build a harmonious and equal relationship between teachers and students. Relying on the subject platform, we can take the combination in class and after class, adopt basic chemistry experiments, extracurricular scientific projects and multi-platform technology innovation. Emphasizing problems as centrality, highlighting teacher's new research results and the independent innovation of students. We require students to solve problems, take part in scientific research projects and innovate through the class experiment, innovative learning team, independent research and other forms, meanwhile, we require teachers to teach students in accordance with their aptitude.

(1) Renewing education concept: Teaching is a process of equal communication, harmonious interaction and coordinated development between teachers and students. Teachers, as the organizers and leaders of teaching activities, pay close attention to the learning process and development of students, meanwhile, they focus on the development of students' comprehensiveness, initiative, the development of the differences and sustainability. With the help of teachers, students can actively carry out independent, inquiry and cooperative learning. To establish new concepts of talents, we requires students to master the basic knowledge and basic skills at the same time, and cultivate students equipped with lifelong learning, cooperative consciousness, the spirits of innovation and the abilities of practice to satisfy the requirements of economic and social development.

(2) Setting up innovative learning team and participating in teacher research projects: We set up innovative learning team by selection. Seniors participate in the whole process of experiment teaching, including the experiment preparation, teaching, the class discussion, the instruction and the correction of experiment text. We determine the goal of innovation according to the requirements of teaching reform and the teachers' scientific research projects. In the innovative experiment, for the more mature projects, we take ways of "Mentoring", namely with the seniors teach the mentees and the good foundation of students to teach the poors. The innovation team held a regular meeting of research results, leaders fully grasp the progresses of the study and deploy the next step of research arrangements. We share and reference good experience, discuss and solve difficult problems together to promote the research work in an orderly manner towards the target of development.

When teachers guide students to participate in scientific research projects, they encourage students to research independently, focus on imparting knowledge, training abilities and improving the quality of coordinated development. Teachers also pay attention to strengthening the spirits of students' exploration, scientific thinking, practice and innovation abilities. Under the condition that the teaching task is heavy, the research funds are insufficient and the equipments are not perfect, we explored initially methods of cultivating innovative talents by closely relying on students, the provincial quality engineering, and carrying out scientific research platform effective.

We keep insisting to improve the students' abilities of innovation, the comprehensive quality, and to update and optimize the contents of the experiment by experimental research. For example, innovation team found the low yield of $\mathrm{K}_{3}\left[\mathrm{Fe}\left(\mathrm{C}_{2} \mathrm{O}_{4}\right)_{3}\right]$ synthesized according to the text book, the members got cracking on studying and applied the correct concentration of solution instead of saturated solution recorded in the text book, which increased productivity and quality significantly. After studying Organic Chemistry, the second-year students were guided by teachers to synthesize the Schiff base, and they were demanded to continue to synthesize new Schiff-base complexes depending on knowledge of Coordination Chemistry. The third-year students had learned thermodynamics in Physical Chemistry, they were further required to design feasible thermochemical cycle based on Hess's Law, and to measure the heat of solution of complexes and other dependences. The data was calculated, written and published in journal, which caused profound impaction on the employment of students and post-graduate studies.

(3) Implementing open and interactive teaching: Based on the integration and refactoring of the experimental contents, teachers adopted the open and interactive ways and used the network space 
to teach. And the teachers established self-study system for students, which helped students to acquire important reference books and literature easily, encouraged students autonomously to choose the experimental contents, to design experimental process and to analysis results under the guidance of teachers.

(4) Carrying out multi-platform extracurricular scientific and technological activities to enhance students' innovative abilities: By college students' chemical experiment skills competition, college students' extracurricular academic science and technology competition and college students' business plan competition as a leader, the students could discovery problems keenly, determine the research topic, collect information widely focused on the issues, seek effective ways to solve the problems of the experiment, and submit the research results at last. We carry out multi-platform scientific and technological innovation activities, stimulate college students' scientific and technological innovation. We are exploring a suitable operation mode of innovation team which is suitable for the actual situation of local colleges and universities.

Evaluating Process and Reforming the Ways of Evaluation. We change the single evaluation system of traditional academic score. The combinations of process evaluation and summative evaluation, final examination and peacetime grade are included in the current system. We randomly select experimental items used in the exam of operation to students, and bring the results of students' research learning, scientific research projects as well as the situations of discipline competitions into overall quality evaluation system. There are a various of ways to perform students' achievements, which can be a research paper, a program demonstration report, a test design, a model, an invention, etc.

\section{Discussion}

(1) As a local university, teachers should make use of the development of science and the application of science and technology to strengthen the construction of teachers' team and stimulate the students' spirits of exploration.

(2) We should actively absorb the experiences of other institutions at home and abroad, refine the framework of experimental teaching system for local universities and further expand the research teaching model of optimization theory.

\section{Acknowledgements}

This work was supported by "the 13th five-year " professional comprehensive reform pilot project of ordinary colleges and universities of Hunan Province \{Xiang Jiao Tong [2016] 276\}.

\section{References}

[1] Sh. Chen, Y.Zh. Su and J.H. Zhao,etc: Experimental Technology and Management,Vol. 29 (2012) No.3, p. 1-4.

[2] Sh.K. Gao, J.Zh. Chen, H.H. Li and X.F. Shi: Experimental Technology and Management, Vol.29 (2012) No.3, p.5-8.

[3] X.Y.Hou, Q.L. Hou, Y.J. Liu, X.K. He: RESEARCH AND EXPLORATION IN LABORATORY, Vol.28 (2009) No.7, p. 88-91.

[4] X.Y. Wang, C.X. Xie, Sh.Zh. Luo, Sh.W.Wang, H.T. Liu and Y. Qi: RESEARCH AND EXPLORATION IN LABORATORY, Vol.33 (2014)No.6, p.186-189.

[5] Y. Qi, Sh.W.Wang, Y.J. Liu, etc: Experimental Technology and Management,2010,Vol.27 (2010) No. p. 144-145,166.

[6] M.Gibbons: Self-directed learning handbook:challenging adolescent students excel (San Francisco:Jossey-Bass,2002). 
[7] P.W.Jackson: Life in classrooms (1968).

[8] M. Knowles: Self-directed learning:A guide for learners and teachers (.Toronto:The Adult Education Company,1975, p.18).

[9] J.Sh.He: Theory and Practice of Education, Vol. 29 (2009) No.1,p.42-44.

[10] B.H.Manning: Cognitive Self-Instruction for Classroom Processes (State University of New York Press, 1991).

[11] W.G. Pang Self-learning: Principles and Strategies of Learning and Teaching ( East China Normal University Press, Shanghai,2003). 